\title{
The Fundamentals And Fun Of Electronic Teamwork For Students And Their Instructors
}

Jeffrey R. Mueller, D. M., National University, USA

\begin{abstract}
This paper reviews and integrates best practices for online teamwork for students and instructors from current and classical literature as well as the author's own six years of online teaching experience (over 40 online courses). A qualitative reflection of six graduate and six undergraduate courses in management, human resource management and organizational development using student teams via the internet were used in this study. An updated model of Tuckman's (1965) team development process is offered. Additional reflection on the use of confidential, student peer ratings are given. Samples of student feedback on the team experience in their courses are summarized along with lessons learned for the instructor and the student.
\end{abstract}

Keywords: Online Teamwork for Students and Instructors; Collaborative Online Assignments; Conflict Management in Online Student Teams; Learning Leadership and Teamwork in the Electronic Classroom

\section{INTRODUCTION}

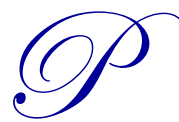

erhaps the greatest skillsets any teacher can impart, regardless of discipline or level of instruction, are those competencies regarding effective teamwork and leadership. After all, the need to collectively solve problems and influence others electronically toward that end is unprecedented in human history given our increased internet connectedness and the economic crises indicative of our current global recession. This paper introduces several ideas for fostering teamwork and leadership in an accelerated electronic classroom. By accelerated, the author means four weeks for the entire course. Therefore, there is very little room for making mistakes.

Moreover, and contrary to the popular use of the term virtual (e.g., Berry, 2011; Staggers, Garcia and Nagelhout, 2008; Schwartzman, 2006; Lam, Chua and Williams, 2005; and many others), the author does not like the word virtual as applied to electronic teams. After all, there is nothing unreal about the real challenges of doing work and teamwork via the computer. The ideas to follow include collaborative online assignments and team agreements; technology; student-led discussion threads; and confidential peer ratings among student teammates.

There is much scholarly literature regarding the teaching of teamwork and leadership in the physical classroom but very little for teaching these important topics online (undergraduate science instruction notwithstanding). "Most of the research on teams is still focused on traditional face-to- face teams (Berry, 2011) and even less on student teams -- except collaborative writing professors Staggers, Garcia and Nagelhout (2008); and communications professor Schwartzman (2006). The importance of teaching online teamwork in the college classroom is highlighted at Figure 1.

1. Exponential growth of electronic business teams (Maznevski and Chuboda, 2000; and Thomas, 2007)

2. Increased speed and agility of information transfer (Berry, 2011)

3. Time and travel savings (Grimshaw and Kwok, 1998)

4. Exponential growth of online classes

Figure 1 - Reasons to Teach Electronic Teamwork in the Classroom 


\section{COLLABORATIVE ONLINE ASSIGNMENTS AND AGREEMENTS}

Bocchi, Eastman and Swift (2004) profiled online MBA students and concluded a need to better equip students to work in electronic teams. Interestingly, these authors also cited research from Kearsey (2002) and Smith (2001) who recommended not more than 20 students in an online course (readers who are university administrators pushing large enrollment classes please take note). Furthermore, Millis and Cottell (1998) recommended a small group size of four. Conrad and Donaldson (2004) published a book on engaging the online learner that included a suggested checklist for team activities (Figure 2)

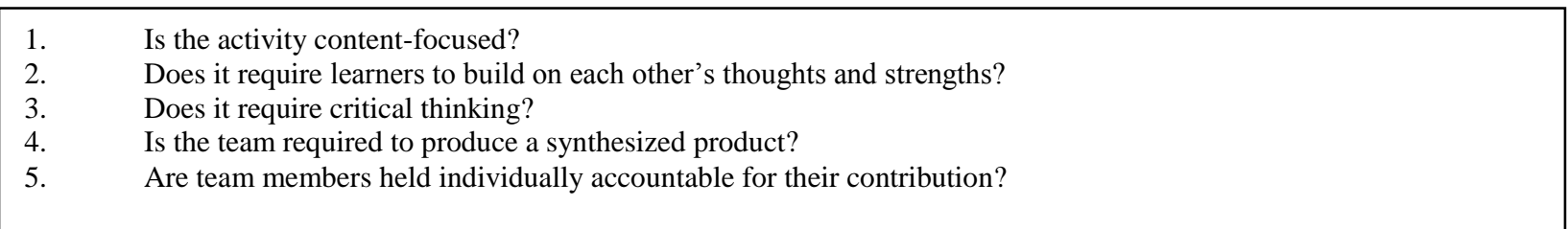

Figure 2 - Checklist for Effective Online Team Assignments

(adapted from Conrad and Donaldson, 2004)

Although suggested assignments were not offered, this checklist guided the author's thinking in constructing meaningful team assignments and feedback. Experiential teamwork and leadership in the online academic medium can be accomplished a number of ways. One way is to challenge students with a collaborative team research assignment worth $20 \%$ of their final grade. Students are randomly put into groups of four or five and told to select a relevant topic (that they must usually narrow to conform to page requirements - ten pages) and comply with other syllabi expectations for academic writing. The selection of the topic is then posted in the discussion board at the end of the first week by the elected team leader along with the team agreement.

This random selection of student teams is labeled by Staggers, Garcia and Nagelhout (2008) as "the biggest challenge we [business writing instructors] face in helping student groups become teams". Their response to this challenge was to require students to 1) become familiar with a condensed version of Tuckman's (1965) classic stages of a team and 2) assign teams and team roles in a mock conference project scenario, their attempt at teambuilding. The author wholeheartedly concurred with their first suggestion (although an expanded version is needed and not a condensed version) and vehemently disagreed with the second, arguing that 1) working students have enough real organizational challenges to occupy their problem-solving propensity and 2) students need to discover their own role within a team.

In lieu of an artificial teambuilding exercise the author recommends a team agreement to specify goals and roles. Gaytan and McEwen (2007) recommended the use of learning contracts, small group work, projects and collaborative learning but did not provide any specific methods or examples for this. Team agreements per Block (2000), the consultant's consultant, are a kind of social contract that describes what team members expect from each other and when. The reason for putting it in writing is for clarity, not enforcement. Therefore, as teammates learn, and learn from, each other's strengths and weaknesses they may revise the roles they choose in order to produce a successful outcome - the project - at the end of the third week of class. Not all students are excellent writers but perhaps they can adopt and learn at least something about writing via the role of APA-compliance editor, content editor, counter-evidence editor (devil's advocate), creativity editor, researcher, meeting leader or some other self-orleader-designated contribution.

Moreover, while the product is important, equally important for learning teamwork and leadership is the team process. Tuckman (1965) introduced a five-step process of group development that has served as an industry training standard since its inception. It was updated by Maples (1988); Staggers, Garcia and Nagelhout (2008) and once again by the author (Figure 3).

Interestingly, the first four stages of this model correspond nicely with what Katzenbach and Smith (2003) defined as "the team performance curve". According to this pair, a team characteristically takes a significant dip in performance shortly after forming and during the storming stage. It is only after the team revisits their team 
agreement (e.g., mission, goals and roles) in the norming stage that they achieve some degree of performance; and maximize their performance based on the conditions listed in the perform section of Figure 3. The performance stage, incidentally, is where the fun of teamwork begins, and only after the preceding stages, the fundamentals, are fulfilled.

Tuckman (1965) argued that groups need to experience every stage to achieve maximum effectiveness but as noted by the Staggers trio (2008) "the stages of teambuilding are recursive and not linear"; hence the double arrows in Figure 3 suggesting the dynamic nature of the model. Additionally they significantly note that Cog's Ladder, an abbreviation of Tuckman (see quotations in Figure 3), is used at U.S. military academies for teaching cadets how to become leaders and officers. Given the prevalence of geographically separated military units scattered around the world, the author wonders if the military academies are teaching online teamwork and leadership, too. In any case, it is sorely needed in global business.

\begin{tabular}{|c|c|c|}
\hline Stage & Characteristics & Action Required \\
\hline $\begin{array}{l}\text { Form } \\
\text { (or reform) } \\
\uparrow\end{array}$ & $\begin{array}{l}\text { courtesy, confusion, } \\
\text { caution, concern; "polite } \\
\text { stage" }\end{array}$ & a draft team agreement to clarify team mission/goals, roles and expectations \\
\hline Storm & $\begin{array}{l}\text { conflict, silent or conveyed } \\
\text { criticism, poor attendance; } \\
\text { lack of listening; lack of } \\
\text { equal contribution; } \\
\text { independence or } \\
\text { over-dependence on } \\
\text { a single person or persons; } \\
\text { "why we're here stage" }\end{array}$ & $\begin{array}{l}\text { confrontation and conflict management/resolution i.e., } \\
\text { 1. acknowledge apparent problem and corresponding emotions } \\
\text { 2. prompt discussion regarding how the conflict is affecting performance } \\
\text { 3. all points of view listened to as objectively as possible } \\
\text { 4. agreement on the problem } \\
\text { 5. invent options for mutual gain } \\
6 . \quad \text { commitment to success/follow-through }\end{array}$ \\
\hline Norm $(-) \uparrow$ & $\begin{array}{l}\text { common team behaviors } \\
\text { that hinder team } \\
\text { performance } \\
\text { (see "storm" above); "bid } \\
\text { for power stage" }\end{array}$ & acknowledge the problem and solve it as indicated above \\
\hline $\begin{array}{l}\text { Norm (+) } \\
\downarrow\end{array}$ & $\begin{array}{l}\text { common team behaviors } \\
\text { that help team performance; } \\
\text { "constructive stage" } \\
\rightarrow\end{array}$ & $\begin{array}{l}\text { acknowledge and reinforce positive contributions and behaviors e.g., a sense of } \\
\text { urgency, continuous learning, information sharing, positive response to change } \\
\text { and challenge, joint decision-making }\end{array}$ \\
\hline $\begin{array}{l}\text { Perform } \\
\downarrow\end{array}$ & $\begin{array}{l}\text { fun; interdependency, } \\
\text { creativity, harmony, } \\
\text { productivity, achievement, } \\
\text { joy; "espirit stage" }\end{array}$ & $\begin{array}{l}\text { exemplary individual and collective creativity and contribution that } \\
\text { consistently exceeds customer/instructor expectations and serves as a model } \\
\text { for other teams. Four conditions are necessary: } \\
\text { 1. complementary skills and experiences } \\
\text { 2. joint goal-setting } \\
\text { 3. joint problem-solving } \\
\text { 4. the collective fun that stems from the preceding }\end{array}$ \\
\hline Adjourn & cohesion, closure; & individual and collective celebration \\
\hline
\end{tabular}
Figure 3 - The Team Development Process

(adapted from Tuckman, 1965; Maples, 1988; Sanborn, 1992; Zenger et al, 1994; Katzenbach and Smith, 2003; and “Cog's Ladder" cited in Staggers, Garcia and Nagelhout, 2008)

This team development process is introduced to students in their first live interactive chat (see Technology section below) so that students may immediately experience the first stages (post-lecture) in their respective team chat rooms. Again, the double arrows in the model represent the dynamic nature of this extended model and the reality of team life. For example, stage two, conflict, is a normal, natural and necessary aspect of team life; indeed life on any scale. Students are told to expect and resolve conflict as it is likely to produce a better product. Related, the absence of conflict may cause the phenomenon groupthink (term coined by Whyte, 1952 and popularized by Irving, 1977) attributed to many team failures and real-life tragedies such as the Space Shuttle Challenger disaster January 28, 1986. Therefore, teams may revert to the conflict stage at any time and this is not necessarily a bad thing as long as one (or the entire team) learns from mistakes and makes progress. 
Stage Three - norming, - is that pre-performance stage where teammates identify and acknowledge those recurring patterns of team behavior that help (positive norms) or hinder (negative norms) the success of the team. Regarding the former, a reinforcement of those positive norms (e.g., deadline timeliness, listening to all ideas, constructive criticism, etc.) is suggested. Regarding the latter, students are cautioned to address and resolve the negative norms (e.g., non-attendance or non-contribution in team meetings, egotism, dominance, etc.) lest their team revert to the former stage - storming - and stay there ad infinitum or ultimately disband (even emotionally) prematurely. Moreover, any time change is introduced to the team, be it a change in team membership or direction, the team may have to revert all the way back to the form stage and literally REform, re-storm, and/or re-norm.

In the performance stage teams emulate exemplary teams as they strive for project completion. As Katzenbach and Smith explained, "overcoming barriers to performance is how groups become teams...surmounting obstacles together builds trust and confidence in each other's capabilities". However, the team learning continues when the professor grades the paper with corresponding detailed feedback based on the all of the previous guidance, particularly Chat One, and, of course, the course outline (syllabus). Sometimes this instructor feedback is where the greatest student revelations occur as student teams realize their product did not meet certain pre-established instructor expectations. In other cases where the team paper met or exceeded instructor expectations, the team further experiences the joy and fun of their collective efforts.

In any case, the final stage - adjourning - students are required to rate their teammates as described in the Confidential Peer Rating section below and record additional reflections on a final exam short-answer question described in the Evaluation section of this paper.

\section{TECHNOLOGY}

The technological platform used at the author's university is e-college. It features group text-chat rooms for synonymous group work that are automatically recorded (archived) for ease of instructor and absent teammate review. E-college also features a drop-down menu in Doc Sharing specifically for team use (and also for instructor/entire class use).

A third feature is the oral interactive chat, also known as Class Live Pro (CLP). Instructors may talk via headset to their students while their students listen in real time and simultaneously review Power Point slides or other shared documents. Students may also ask questions to anyone present if their headset has a microphone thereby immediately addressing any concerns or comments. CLP also contains a text chat area for those students having technical difficulties with their headsets or did not purchase a headset. In any case, the live lecture/discussion, and text chat are automatically recorded so that absent students may review, learn and contribute ex post facto to the archives at their convenience.

Student teams are required to use all three of these e-college features (in lieu of the many other options available) so that the author may take a peek at group dynamics and progress, and comment accordingly, much as instructors would do in an onsite classroom. Additionally, student teams can conduct live, interactive discussion via headset if the instructor logs on as moderator and grants moderator privileges to the team members. The instructor does not have to be present for the whole meeting, only the set-up.

E-college also features a text feedback section in the grade book for individual feedback on all assignments as well as an announcement feature for collective/class feedback such as posting the range and mean scores of all assignments. In the latter, students can see how they are doing in comparison to their anonymous peers if the instructor uses these features.

The telephone is highly recommended for teams in the event of significant disagreement between team members (and/or their instructor); and perhaps group conference calls if students have access to that technology. After all, the telephone offers the additional richness (e.g., tone of voice, etc.) and immediacy not present in exclusively text-based or other asynchronous media. 


\title{
STUDENT-LED DISCUSSION THREADS
}

\author{
Bender (2003) reported,
}

it is only through online discussion that the instructor can come to know the students, and know how they think... pulling together disparate strands of conversations, expertly weaving the different threads to make a cohesive body of knowledge which can move forward in a linear fashion...leads to meaningful learning as well as richness and diversity of thought and discussion

Why not have students choose relevant discussion questions in the final week(s)? The first five students who $\log$ on have the option of doing so. All of the other "rules" apply for the entire class (including discussion leaders): alternate day posting, integrated research and textbook ideas (including sources), minimum two classmate interaction, spell check and grammar check, etc. Student discussion leaders are sent an email requesting they follow certain leadership practices (see Figure 4).

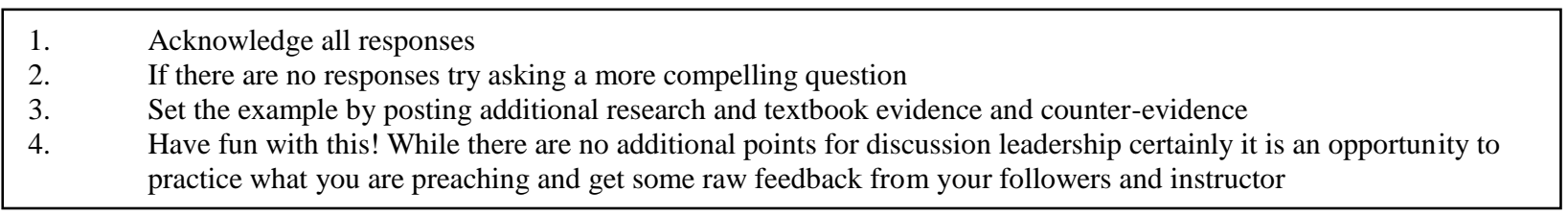

Figure 4 - Student Discussion Leadership

\section{CONFIDENTIAL PEER RATINGS (CPRS)}

Multi-rater feedback, also known as 360 Assessment, has become increasingly popular in industry for good cause: it adds transparency and equity not seen in exclusively top-down, frequently-biased feedback and performance appraisal systems. The author's approach to this in the electronic classroom is to have students rate each other on a scale of $0-4$ (see Figure 5) based exclusively on contribution to the team research project. Students do not rate themselves and are cautioned to keep their ratings confidential. As Edwards and Ewens (1996) stated, " $360^{\circ}$ feedback systems must guarantee absolute anonymity to respondents and confidentiality to employees [students] regarding their feedback, or the process will fail”.

Students are required to submit CPRs, whole numbers only with brief justification, to the instructor via email after the project is submitted and before they receive the graded feedback. Scores are tallied by the instructor and rounded up if the mean is .5 or above or down if below .5. The CPR is worth up to four percent of their final grade. Failure to complete the CPR assignment forfeits the points for it.

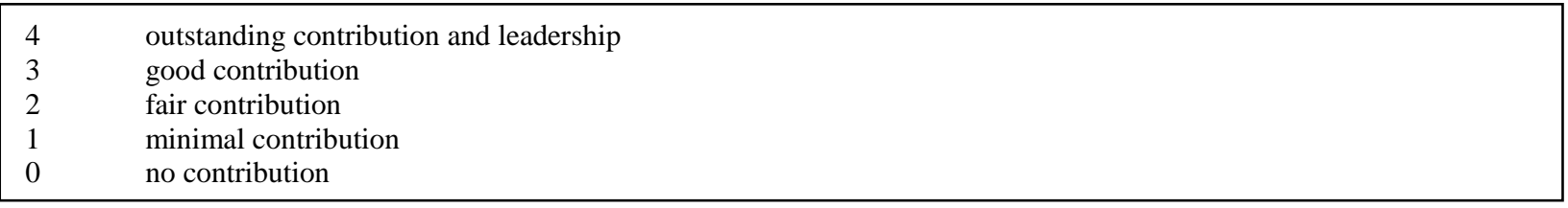

Figure 5- Confidential Peer Ratings

\section{SUMMARY AND CONCLUSION}

The final exam question that yielded student reaction to the online team experience was given to them several days before the exam to allow thoughtful reflection. All students receive the point for the question as long as they answered it: In a single paragraph detail your reaction to and use of team tools (team agreement, chat room, doc sharing, etc.) as well as the team experience. E-college conveniently records the collective answers for ease of display and review. The overall reaction to the use of tools and technology was very positive in this sample of twelve graduate and undergraduate courses, particularly the use of the team agreement and paper guidance. Conversely, the team experience varied depending on the teammates. Most of the criticism had to do with meeting 
teammates via different time zones and social loafing (rightfully exposed in the confidential peer ratings). Isn't that reality? In any case, students now know what it is like to participate on an electronic team, produce a team document, experience and/or resolve team conflict if any, lead a threaded discussion, and evaluate their peers based on contribution. Hence, they are more prepared for electronic teamwork and leadership on-the-job as compared to employees who have not worked on electronic teams.

The approach listed in Figure 6 virtually eliminates the "real problems with virtual teams" (Lam, Chua and Willimas, 2005) namely, "lack of coordination, minimal interaction, 'get it over with' mentality, lack of deep discussion, clinical rather than heated discussion, dormant teams, free-riders and easy-riders". It also counters the findings of Tinoca and Pereira (2010) that "special care must be given to the construction of groups". Rarely do business teams get to choose their teammates. Lastly, these fundamentals resolve the critical praxis suggested by Seibold and Kang (2008), "teaching a process involving a continuous relationship between practice and reflexivity".

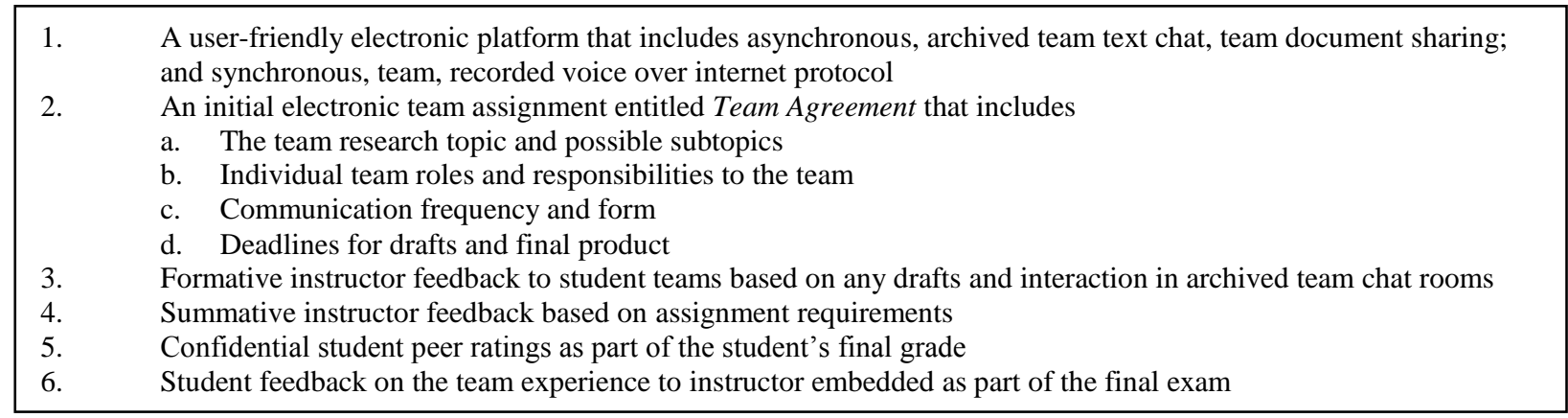

Figure 6 - The Fundamentals of Electronic Teamwork

\section{LIMITATION OF THE STUDY AND FUTURE STUDIES}

How well this set of online team experiences in academia translate back into the world of work will need to be evaluated via longitudinal studies and their introduction here paves the way for that. Moreover, the author strongly recommends hybrid courses (a combination of online and onsite) in lieu of exclusively online courses for maximum learning of these topics. After all, interpersonal skills and presentation skills cannot be effectively taught or learned exclusively online (Mueller and Marandos, 2008). Nevertheless, transfer of online learning from several undergraduate and graduate courses in management, human resource management and organizational development will be tested via a Likert-scale survey to class alumni planned for 2015 (email addresses have been retained). In the spirit of online teamwork and leadership the author invites ongoing dialogue and feedback to Email: jmueller@nu.edu. Together we can make a lasting difference in the minds and team behaviors of these dedicated student-leaders and future leaders.

\section{AUTHOR INFORMATION}

Jeffrey R. Mueller, D.M. is an associate professor and regional lead faculty in the Leadership and Human Resource Department in the School of Business and Management at National University. His research interests include leadership development, organizational development, change management, organizational behavior and misbehavior, organizational redesign, staffing, training, performance management, multiple intelligences and the use of music and other interdisciplinary approaches as a method and a metaphor in all the above. He invites comments to E-mail: jmueller@nu.edu

\section{REFERENCES}

1. Bender, T. (2003) Discussion Based Online Teaching to Enhance Student Learning. Sterling, VA: Stylus Publishing.

2. Berry, G.R. (2011) Enhancing Effectiveness on Virtual Teams. Journal of Business Communication Vol. 48, Number 2. 
3. Block, P. (2000) Flawless Consulting. San Francisco: Jossey-Bass.

4. Bocci, J. Eastman, J.K. and Swift, C.O. (March/April 2004) Retaining the Online Learner. Journal of Education for Business.

5. Conrad, R-M. and Donaldson, J.A. (2004). Engaging the Online Learner. San Francisco: Jossey-Bass.

6. $\quad$ Edwards, M.R. and Ewen, A.J. (1996) 360 Degree Feedback. NY: Amacom

7. Gaytan, J. and McEwen, B.C. (2007) Effective Online Instructional and Assessment Strategies. The American Journal of Distance Education 21 (3).

8. Grimshaw, D.J. and Kwok, F.T.S. (1998). The business benefits of the virtual organization. In The Virtual Workplace by editors Igbaria, M. and Tan, M. Hershey, PA: Idea Group.

9. Hannah, S.T., Walumba, F.O., and Fry, L.W. (2011). Leadership in action teams: team leader and members' authenticity, authenticity strength, and team outcomes. Personnel Psychology 64, 771-802.

10. Janis, I.L. (1982) Groupthink: Psychological Studies of Policy Decisions and Fiascoes. Boston: HoughtonMifflin.

11. Judeh, M. (2011). An examination of the effect of employee involvement on teamwork effectiveness: an empirical study. International Journal of Business and Management Vol. 6, No. 9.

12. Katzenbach, J.R. and Smith, D.R. (2003) The Wisdom of Teams. NY: HarperCollins.

13. Kearsley, G. (2002 Jan/Feb). Is online learning for everybody? Educational Technology, 42(1).

14. Lam, W., Chua, A., Williams, J.B. (2005). Real problems with virtual teams: an analysis of the factors leading to dysfunctional online collaboration. U21Global Working Paper No.005.

15. Maples, M.F. (1988) Group Development: Extending Tuckman's Theory. Journal for Specialists in Group Work, 13.

16. Maznevski. M.L. and Chuboda, K. (2000). Building space over time: Global virtual team dynamics and effectiveness. Organizational Science 11, 473-492.

17. Millis, B.J. and Cottell, P.G. (1998).Cooperative learning for higher education faculty. Phoenix, AZ: Oryx Press.

18. Mueller, J.R. and Marandos, S.A. (2008). Hybrids: How effective are they in tapping into students' learning styles and instructor teaching preferences v. exclusively online courses? American Society of Business and Behavioral Sciences Conference Proceedings.

19. Sanborn, M. (1992) TeamBuilt. New York: MasterMedia Limited.

20. Schwartzman, R. (2006). Virtual Group Problem Solving in the Basic Communication Course: Lessons for Online Learning. Journal of Instructional Psychology 33 3-14.

21. Seibold, D.R., and Kang, P. (2008). Using critical praxis to understand and teach teamwork. Business Communication Quarterly, Vol. 71, Number 4.

22. Smith, L.J. (2001) Content and Delivery: a comparison and contrast of electronic and traditional MBA marketing planning courses. Journal of Marketing Education 23 (1).

23. Staggers, J., Garcia, S., and Nagelhout, E. (2008). Teamwork through team building: face-to-face to online. Business Communication Quarterly, Vol. 71, Number 4.

24. Sweet, M. and Michaelsen, L.K. (2007) How Group Dynamics Research Can Inform the Theory and Practice of Postsecondary Small Group Learning. Educational Psychology Review 19: 31-47.

25. Thomas, G.F. (2007). How can we make our research more relevant? Bridging the gap between workplace changes and business communication research. Journal of Business Communication, 44 283-296.

26. Tinoca, L. and Pereira, A. (2010). Online group work patterns: how to promote a successful collaboration. Proceedings of the $7^{\text {th }}$ International Conference Networked Learning.

27. Tuckman, B.W. and Jensen, M.A.C. (1977) Stages of Small Group Development Revisited. Group and Organization Studies 2.

28. Zenger, J.H., Musselwhite, E., Hurson, K. and Perrin, C. (1994) Leading Teams. NY: Irwin. 
NOTES 